\title{
PENGARUH DISIPLIN PENGENDARA KENDARAAN BERMOTOR TERHADAP KESELAMATAN BERLALU LINTAS DI KOTA BOGOR
}

\section{INFLUENCE OF DISCIPLINE RIDERS PASS MOTOR VEHICLE SAFETY OF TRAFFIC IN BOGOR}

\author{
Rahmat Saepul Turohman ${ }^{1}$, Abubakar Iskandar ${ }^{2}$, Muhamad YGG. Seran ${ }^{3}$
}

\begin{abstract}
1 Jurusan Ilmu Administrasi Negara Fakultas Imu Sosial dan Ilmu Politik Universitas Djuanda, Jl.Tol Ciawi No 1, Kotak Pos 35 Bogor 16770

2 Jurusan Ilmu Administrasi Negara Fakultas Imu Sosial dan Ilmu Politik Universitas Djuanda, Jl.Tol Ciawi No 1, Kotak Pos 35 Bogor 16770

3 Jurusan Ilmu Administrasi Negara Fakultas Imu Sosial dan Ilmu Politik Universitas Djuanda, Jl.Tol Ciawi No 1, Kotak Pos 35 Bogor 16770
\end{abstract}

(Diterima oleh Dewan Redaksi: 01-02-2017)

(Dipublikasikan oleh Dewan Redaksi: 01-04-2017)

\begin{abstract}
The purpose of this study are to describe the discipline of motor vehicle drivers in traffic and the level of traffic safety in Bogor City, to analyze the effect of discipline motorists against motor vehicle safety in Bogor, to describes the efforts undertaken Bogor City Government cq. DLLAJ city of Bogor in improving discipline of motorists against motor vehicle safety in Bogor. Methods used are descriptive and associative method. The data used are primary data and secondary data. Primary data is collected by distributing a questionnaire, and supported by the observations and interviews. The collection of secondary data sourced from documents, literature and related research. The sampling technique is simple random sampling that amounted to 56 motorists on the three streets are: Jl.Raya Tajur as many as 20 riders, 16 riders from Jl.KS Tubun, and 20 riders from Jl.Jalak Harupat. Based on the correlation coefficient between the disciplines of motor vehicles with safety in traffic amounted to 0.513 and the interpretation is quite strong, and the positive direction indicates that the variable of riders discipline with variable of safety is significant correlation, means that the higher discipline the higher the level of safety. That correlation between the variable X (Discipline) with Y (Safety) is significant at an error rate of $0.01(1 \%)$ and $99 \%$ confidence. Based on the conclusion, the author recommend: the Department of Transportation in Bogor through the Section of Communication, Information, Education and Communications-Section Guidance and Safety in order to continue disseminating safety riding, and equipping of road infrastructure such as mounting traffic signs, road markers, tool of speed limit, a safety device road users to improve road safety.
\end{abstract}

Keywords: High-Discipline, safety drive, the higher discipline the higher the level of safety

\section{ABSTRAK}

Tujuan dari penelitian ini Mendeskripsikan Disiplin Pengendara Kendaraan Bermotor dalam berlalu lintas dan tingkat Keselamatan Berlalu lintas di Kota Bogor. Menganalisis Pengaruh Disiplin Pengendara Kendaraan Bermotor Terhadap Keselamatan Berlalulintas di Kota Bogor. Menjelaskan Upaya-Upaya yang dilakukan Pemerintah Kota Bogor cq. DLLAJ Kota Bogor dalam meningkatkan Disiplin Pengendara Kendaraan 
Bermotor Terhadap Keselamatan Berlalulintas di Kota Bogor. Metoda yang digunakan: metode deskriptif dan asosiatif. Jenis data yang digunakan adalah data primer dan data sekunder. Data primer dikumpulkan dengan menyebarkan angket, lalu didukung dengan pengamatan dan wawancara. Pengumpulan data sekunder bersumber dari dokumen, pustaka dan riset terkait. Teknik pengambilan sampel: sampel penelitian berjumlah 56 orang pengendara kendaraan bermotor dari tiga ruas jalan diantaranya: Jl.Raya Tajur sebanyak 20 orang pengendara, Jl.KS Tubun 16 orang pengendara, Jl.Jalak Harupat 20 orang pengendara. Berdasarkan Koefisien korelasi antara disiplin kendaraan bermotor dengan keselamatan berlalu lintas sebesar 0,513 intepretasi cukup kuat, dan arah positif menunjukan bahwa variable Disiplin pengendara dengan variable Keselamatan berkorelasi secara signifikan artinya semakin tinggi disiplin semakin tinggi pula tingkat keselamatan, bahwa korelasi antara variable X ( Disiplin ) dengan Y ( Keselamatan ) adalah signifikan pada tingkat kesalahan 0,01 (1\%) dan kepercayaan 99\%. Berdasarkan kesimpulan maka penulis memberikan saran: Dinas Perhubungan Kota Bogor melalui Seksi Komunikasi, Informasi dan Edukasi Perhubungan/ Seksi Bimbingan dan Keselamatan agar terus melakukan sosialisasi dartiblantas, safety riding, dan melengkapi prasarana jalan seperti pemasang rambu-rambu lalulintas, marka jalan, alat pembatas kecepatan, alat pengaman pemakai jalan guna meningkatkan keselamatan lalulintas.

Kata Kunci : Semakin Tinggi Disiplin Semakin Tinggi Pula Tingkat Keselamatan dan sebaliknya.

Rahmat Saepul Turohman, 2017, Pengaruh Disiplin Pengendara Kendaraan Bermotor Terhadap Keselamatan Berlalulintas di Kota Bogor. Jurnal Governansi. 


\section{PENDAHULUAN}

Pertumbuhan jumlah kendaraan di jalan raya begitu pesat, hal ini cukup beresiko untuk terjadinya kecelakaan. Berdasarkan perkiraan organisasi kesehatan dunia (WHO) sekitar 1,2 juta orang meninggal dunia, 50 juta orang diantaranya mengalami luka berat dan luka ringan setiap tahunnya akibat kecelakaan. Lebih lanjut diperkirakan tahun 2020 kecelakan jalan merupakan penyebab terbesar ketiga kematian diseluruh dunia setelah penyakit jantung dan depresi (sumber: PUSBANG SDM PERHUBUNGAN Tahun 2014).

Penyebab kecelakaan lalulintas di Indonesia yang paling besar adalah factor manusia 89,50 \%, dimana peran manusia sebagai pengemudi $82,39 \%$ dan sebagai pejalan kaki 7,11 \%, factor kendaraan 4,80 $\%$, serta factor jalan raya $5,05 \%$, dan lingkungan $0,65 \%$. Untuk sumber daya manusia permasalahannya disebabkan oleh disiplin berlalulintas, rendahnya akan keselamatan, dan belum memadainya kompetensi petugas bidang keselamatan (Sitorus,1992).

Tabel 1.

Data Kecelakaan Lalu Lintas di Kota Bogor

\begin{tabular}{|c|c|c|c|c|c|c|c|c|c|c|c|}
\hline \multirow{3}{*}{ NO } & \multirow{3}{*}{ TAHUN } & \multirow{2}{*}{\multicolumn{2}{|c|}{$\begin{array}{c}\text { KEEADIAN } \\
\text { KECEELAKAAN }\end{array}$}} & \multicolumn{6}{|c|}{ KORBAN } & \multirow{2}{*}{\multicolumn{2}{|c|}{ KERUGIAN MATERI }} \\
\hline & & & & \multicolumn{2}{|c|}{$\begin{array}{c}\text { MENNGGGLL } \\
\text { DUNAA }\end{array}$} & \multicolumn{2}{|c|}{ LUKA BERAT } & \multicolumn{2}{|c|}{ LUKA RINGAN } & & \\
\hline & & Jumlah & $\%$ & Jumlah & $\%$ & Jumlah & $\%$ & Jumlah & $\%$ & Jumlah & $\%$ \\
\hline & 2011 & 75 & & 31 & & 41 & & 54 & & $317,200,000$ & \\
\hline & 2012 & 171 & $128.00 \%$ & 48 & $54.84 \%$ & 61 & $48.78 \%$ & 137 & $153.70 \%$ & $745,150,000$ & $134.91 \%$ \\
\hline & 2013 & 235 & $37.43 \%$ & 54 & $12.50 \%$ & 80 & $31.15 \%$ & 210 & $53.28 \%$ & $749,150,000$ & 0.54 \\
\hline & 2014 & 142 & $.39 .57 \%$ & 38 & $.29 .63 \%$ & 48 & $-40.00 \%$ & 129 & $.38 .57 \%$ & $446,050,000$ & $-40.46 \%$ \\
\hline & 2015 & 100 & $.29 .58 \%$ & 27 & $.28 .95 \%$ & 22 & $.54 .17 \%$ & 104 & $.19 .38 \%$ & $340,000,000$ & -23.780 \\
\hline & PENNN & & $24.07 \%$ & & $8.44 \%$ & & $-4.91 \%$ & & $32.71 \%$ & & $33.61 \%$ \\
\hline
\end{tabular}

rata satu juta pertahun akibat kecelakaan $75 \%$ terjadi di negara berkembang kerugian mencapai 2\% GDP (US \$ 100 milyar) nasional korban meninggal ratarata 32 0rang/ hari mungkin sudah dapat dikategorikan endemik kerugian sekitar 30,82 triliun rupiah atau sekitar $2.17 \%$ dari GDP Indonesia. Dari data kecelakaan tersebut diatas didominasi oleh sepeda motor dengan bobot $64 \%$, mobil penumpang $15 \%$, mobil barang $15 \%$, bus $5 \%$, dan kendaraan khusus 1\%. Hal ini disebabkan karena faktor manusia $90 \%$, kendaraan $6 \%$, jalan $3 \%$, lingkungan $1 \%$.

Tabel 2.

Data Pelanggaran Lalu Lintas di Kota Bogor

\begin{tabular}{|c|c|c|c|c|c|}
\hline \multirow{2}{*}{ No } & \multirow{2}{*}{ Periode } & \multicolumn{2}{|c|}{ Tahun 2015} & \multicolumn{2}{|c|}{ Tahun 2016} \\
\hline & & Jml & $\%$ & Jml & $\%$ \\
\hline 1 & Januari & 1.454 & & 2.316 & \\
\hline 2 & Pebruari & 2.480 & 170,56 & 3.893 & 168,09 \\
\hline 3 & Mar & 3.397 & 136 & 1.926 & 49,47 \\
\hline 4 & April & 2.616 & $77,01 \%$ & 2.691 & 139,72 \\
\hline 5 & Mei & 3.504 & 133,94 & 5.961 & 221,52 \\
\hline 6 & Juni & 4.701 & 134,16 & 3.369 & 56,52 \\
\hline 7 & Juli & 1.794 & 38,16 & 2.082 & 61,80 \\
\hline 8 & Agustus & 3.010 & 167,78 & 4.331 & 208,02 \\
\hline 9 & September & 4.170 & 138,54 & 3.727 & 86,05 \\
\hline 10 & Oktober & 4.376 & 104,94 & - & \\
\hline 11 & Nopember & 7.484 & 171,02 & - & \\
\hline 12 & Desember & 2.335 & 31,20 & - & \\
\hline & Jumlah & 41.321 & 118,57 & 30.296 & 123,90 \\
\hline \multicolumn{3}{|c|}{$\begin{array}{r}\text { Rata}^{2} \text { Peningkatan } \\
\text { Pelanggaran }\end{array}$} & \multicolumn{3}{|c|}{$121,24 \%$} \\
\hline
\end{tabular}

Sumber : Satlantas Polresta Bogor Kota Tahun 2016.

Berdasarkan data pelanggaran lalu lintas di Kota Bogor dari bulan Januari 2015 sampai September 2016 sebagaimana tercantum pada tabel 4, menunjukkan bahwa jumlah pelanggaran lalu lintas terjadi peningkatan rata-rata $121,24 \%$ perbulan, artinya tingkat disiplin pengendara menurun.

Sepeda motor dapat menjadi ancaman terbesar terhadap kecelakaan yang terjadi di jalan dan menjadi penyumbang korban tertinggi. Setidaknya 
delapan dari sepuluh kecelakaan lalulintas yang terjadi melibatkan sepeda motor. Kemudahan untuk mendapatkan sepeda motor tidak dibarengi dengan kesadaran para pengguna sepeda motor untuk selalu berkendara dengan aman. Masih banyak pengendara sepeda motor dijalan yang membawa sepeda motornya dengan ugalugalan yang dapat membahayakan orang lain dan tentunya dirinya sendiri. Lebih dari $50 \%$ kecelakaan sepeda motor disebabkan oleh kurang disiplinnya pengendara, dan selain oleh factor pengendara adalah faktor lingkungan. Setiap kecelakaan sepeda motor yang terjadi bisa juga diakibatkan oleh tiga factor yakni, kurangnya pengetahuan tentang peraturan perundangundangan, cara berkendara yang baik dan rambu-rambu lalu lintas (sumber: KORLANTAS POLRI Tahun 2012).

Dengan memperhatikan faktorfaktor penyebab kecelakaan lalu lintas, ketidak-seimbangan antara pertumbuhan sarana dan prasarana serta tingkat disiplin pengendara kendaraan bermotor terjadi penurunan sebagaimana tersebut diatas, maka perlu upaya-upaya yang harus dilakuan oleh pemerintah, khususnya untuk mengatasi masalah kecelakaan dan masalah peningkatan disiplin pengendara kendaraan bermotor, diantaranya melalui program peningkatan keselamatan berlalu lintas, seperti halnya dengan mensosialisasikan kesadaran, ketertiban lalu lintas (Dartiblantas), keselamatan berkendaraan (safety riding), optimalisasi pemasangan prasarana lalu lintas dan kegiatan lainnya.

Mengingat pentingnya disiplin pengendara kendaraan bermotor dan keselamatan berlalu lintas, maka penulis tertarik untuk membahasnya dengan harapan dapat mengetahui korelasi atau hubungan antara keduanya, yang dituangkan dalam skripsi yang berjudul: Pengaruh Disiplin Pengendara Kendaraan Bermotor Terhadap Keselamatan Berlalulintas diKota Bogor.

\section{MATERI DAN METODE}

Menurut Soegeng Prijodarmito (1994:23). Disiplin adalah suatu kondisi yang tercipta dan terbentuk melalui proses dari serangkaian perilaku yang menunjukan nilai-nilai ketaatan, kepatuhan, kesetiaan, keteraturan daan ketertiban. dari definisi tersebut dapat disimpulkan bahwa sikap disiplin merupakan sikap yang dibentuk dengan melewati beberapa proses sehingga terciptanya keteraturan dalam kehidupan sehari-hari.

Menurut Malayu S.P. Hasibuan (2014:193). Disiplin adalah kesadaran dan kesediaan seseorang yang secara sukarela mentaati semua peraturan perusahaan dan norma-norma sosial yang berlaku.

Dari kedua pendapat tersebut diatas dapat disimpulkan bahwa pengertian disiplin adalah ketaatan seseorang terhadap peraturan dan norma yang berlaku.

Menurut T. Hani Handoko (2012:208). Disiplin adalah kegiatan manajemen untuk menjalankan standarstandar organisasional. tipe kegiatan Disiplin yaitu : Disiplin preventip adalah kegiatan yang dilaksanakan untuk mendorong para karyawan agar mengikuti berbagai standard dan aturan, sehingga dapat mencegah terjadinya penyelewengan.

Disiplin korektif adalah kegiatan yang diambil untuk menangani pelanggaran terhadap aturan-aturan dan mencoba untuk menghindari pelanggaranpelanggaran lebih lanjut.

Perusahaan dapat menerapkan suatu kebijaksanaan disiplin progresip, yang berarti memberikan hukuman yang lebih berat terhadap pelanggaran-pelanggaran yang berulang.

Menurut Undang-Undang No. 22 tahun 2009 bahwa keselamatan lalulintas angkutan jalan adalah suatu keadaan terhindarnya setiap orang dari risiko kecelakaan selama berlalulintas yang 
disebabkan oleh manusia, kendaraan, jalan, dan/ atau lingkungan.

Kecelakaan (accident) adalah kejadian yang tak terduga dan tidak diharapkan (Ismoyo Djati, 2001). Kecelakaan lalu lintas adalah kejadian dimana sebuah kendaraan bermotor tabrakan dengan benda lain dan menyebabkan kerusakan.

\section{Populasi dan Sampel}

Populasi adalah wilayah generalisasi yang terdiri atas: objek/subjek yang mempunyai kualitas dan karakteristik tertentu yang ditetapkan oleh peneliti untuk dipelajari dan kemudian ditarik kesimpulannya. (Sugiyono 2012: 90).

Menurut Sugiyono (2012:

91)

Sample adalah bagian dari jumlah dan karakteristik yang dimiliki oleh populasi tersebut. Bila populasi besar, dan peneliti tidak mungkin mempelajari semua yang ada pada populasi, misalnya karena keterbatasan dana, tenaga dan waktu, maka peneliti dapat menggunakan sampel yang diambil dari populasi itu. Sampel penelitian ini adalah: Sebagian pengendara kendaraan bermotor yang berjumlah 56 orang. dari tiga ruas jalan diantaranya: Jl.Raya Tajur sebanyak 20 orang pengendara, Jl.KS Tubun 16 orang pengendara, Jl.Jalak Harupat 20 orang pengendara.

Untuk menentukan jumlah sampel digunakan rumus Yamane (Sukandar rumidi, 2012:56) berdasarkan rumus yamane jika populasi pengendara kendaraan bermotor sebanyak 131,589 dengan tingkat kesalahan ( Eror Margin $10 \%$ ) maka didapat sampel 56 pengendara.

\section{Teknik Analisis Data}

Analisa data adalah proses mencari dan menyusun secara sistematis data yang diperoleh dari hasil wawancara, catatan dari lapangan dan dokumentasi dengan cara mengorganisasikan data ke dalam kategori, menjabarkan ke dalam unit-unit, menyusun ke dalam pola, memilih mana yang penting dan yang akan dikaji dan dipelajari, serta membuat kesimpulan sehingga mudah dipahami oleh diri sendiri maupun orang lain. Proses analisis data ini dilakukan sejak sebelum memasuki lapangan (locus), dan kemudian analisis data terfokus selama proses dilapangan, data yang diperoleh kemudian akan di analisis sehingga dapat diperoleh suatu skesimpulan dari keseluruh data. Teknik analisa data dalam penelitian ini menggunakan rumus yang disampaikan oleh Siregar (1993:35) yaitu rumus WMS ( Weigh Mean Skor ).

$$
\sum \mathrm{M}=\frac{}{n}
$$

Keterangan :

M : Rata-rata Jawaban

f : Frekwensi Jawaban Respoden

$\mathrm{x} \quad$ : Kategori Penilaian

n : Jumlah Responden

$\sum \quad$ : Lambang Penjumlahan.

Untuk mengetahui criteria penapsiran dilakukan dengan cara menghitung interval nilai, yaitu sebagai berikut:

\section{Tabel.1 Kriteria penafsiran}

\begin{tabular}{|r|l|l|}
\hline No. & $\begin{array}{l}\text { Angka } \\
\text { Penafsiran }\end{array}$ & $\begin{array}{l}\text { Kriteria } \\
\text { Penilaian }\end{array}$ \\
\hline 1. & $0,00-0,50$ & Rendah \\
\hline 2. & $0,51-1,00$ & Tinggi \\
\hline
\end{tabular}

Sumber: Metode Penelitian Administrasi (Sugiyono 2012).

Sedangkan untuk menguji hipotesis dari penelitian ini digunakan rumus Korelasi Spearman Rank dengan bantuan aplikasi SPSS (Statistical Product and Service Solutions) Yaitu Mengaplikasikan statistik mengelola dan menganalisis data berbagai keperluan dengan menggunakan Teknik Statistik.

Selanjutnya untuk menguji tingkat keberhasilan pengaruh kedua variable maka digunakan urus uji - t hitung dengan rumus sebagi berikut: Untuk memberikan interpretasi seberapa kuat atau lemahnya 
variabel, maka digunakan pedoman interpretasi koefisien korelasi Sugiyono (2012:214). Maka penulis menggunakan kriteria tersebut dengan pedoman tabel sebagai berikut:

Tabel. 3.5

Pedoman untuk memberikan Interpretasi Koefisien Korelasi

\begin{tabular}{|l|l|}
\hline $\begin{array}{l}\text { INTERVAL } \\
\text { KOEFISIEN }\end{array}$ & $\begin{array}{l}\text { TINGKAT } \\
\text { HUBUNGAN }\end{array}$ \\
\hline $0,00-0,200$ & Sangat \\
$0,201-0,400$ & Rendah \\
$0,401-0,600$ & Rendah \\
$0,601-0,800$ & Sedang \\
$0,801-1,000$ & Kuat \\
& Sangat Kuat \\
\hline
\end{tabular}

Sumber: Metode Penelitian Administrasi (Sugiyono 2012).

Untuk menguji signifikansi pengaruh, yaitu apakah pengaruh yang ditemukan itu berlaku untuk seluruh populasi, maka perlu diuji signifikasinya.

\section{HASIL DAN PEMBAHASAN}

Untuk mengetahui Disiplin menurut T. Hani Handoko (2012:208). Disiplin adalah kegiatan manajemen untuk menjalankan standar-standar organisasional. tipe kegiatan Disiplin yaitu: Disiplin Preventip, Disiplin Korektip, Disiplin Progresip.

\section{Tabel 3}

\section{Rekapitulasi untuk variabel Disiplin pengendara kendaraan bermotor}

\begin{tabular}{|c|l|c|}
\hline NO & \multicolumn{1}{|c|}{ Dimensi } & $\begin{array}{c}\text { Rata-rata } \\
\text { skor }\end{array}$ \\
\hline 1. & $\begin{array}{l}\text { Disiplin } \\
\text { Preventif }\end{array}$ & 0,50 \\
\hline 2. & $\begin{array}{l}\text { Disiplin } \\
\text { korektif }\end{array}$ & 0,70 \\
\hline 3 & $\begin{array}{l}\text { Disiplin } \\
\text { Progresif }\end{array}$ & 0,53 \\
\hline & Rata-rata skor & 0,57 \\
\hline
\end{tabular}

Berdasarkan tabel diketahui nilai ratarata untuk Varabel disiplin adalah sebesar 0,57 dengan kriteria penilaian tinggi, artinya penilaian responden tentang suatu kegiatan yang dilakukan untuk melatih diri dalam melaksanakan kegiatan dengan baik dan benar secara garis besar adalah cukup baik. Hal ini menunjukan bahwa disiplin pengendara kendaraan bermotor ditinjau dari variabel disiplin cukup baik, artinya pengendara kendaraan bermotor dinilai cukup baik dalam menyadari pentingnya disiplin berlalu lintas.

a. Keselamatan Lalulintas angkutan jalan menurut Undang-Undang No. 22 tahun 2009 adalah suatu keadaan terhindarnya setiap orang dari risiko kecelakaan selama berlalulintas yang disebabkan oleh: manusia, kendaraan, jalan, dan/ atau lingkungan.

Tabel 4

Rekapitulasi untuk Variabel Keselamatan Berlalulintas

\begin{tabular}{|l|l|l|}
\hline NO & Dimensi & Rata-rata skor \\
\hline 1. & Manusia & 0,39 \\
\hline 2. & Jalan & 0,26 \\
\hline 3. & $\begin{array}{l}\text { Sarana/ } \\
\text { Prasarana }\end{array}$ & 0,69 \\
\hline 4. & Lingkungan & 0,73 \\
\hline & Rata-rata skor & 0,52 \\
\hline
\end{tabular}

Berdasarkan tabel diketahui nilai ratarata untuk Varabel keselamatan adalah sebesar 0,52 dengan kriteria penilaian tinggi, artinya penilaian responden tentang suatu keadaan terhindarnya setiap orang dari risiko kecelakaan selama berlalulintas yang disebabkan oleh manusia, kendaraan, jalan, dan/ atau lingkungan secara garis besar adalah cukup baik. Hal ini menunjukan bahwa variabel keselamatan cukup baik, artinya pengendara kendaraan bermotor dinilai cukup baik dalam meningkatkan keselamatan berlalu lintas.

\section{Pengaruh Disiplin Pengendara Kendaraan Bermotor Terhadap Keselamatan Berlalulintas di Kota Bogor.}

Untuk menguji pengaruh disiplin terhadap keselamatan digunakan rumus Korelasi Rank Spearman melalui bantuan 
SPSS Versi 22.0. Hasil perhitungan korelasi Rank Spearman disusun berdasarkan kriteria-kriteria yang dibutuhkan dalam upaya mencari hubungan pengaruh, ada atau tidaknya hubungan antara disiplin dengan keselamatan, berdasarkan responden pada keseluruhan ruas jalan dan pada masing-masing ruas jalan yang diteliti yaitu ruas Jl. Raya Tajur, Jl. Jalak Harupat dan Jl. K.S. Tubun, sebagaimana dapat dilihat pada tabel berikut ini :

\section{Nonparametric Correlations}

\begin{tabular}{|c|c|c|c|c|}
\hline \multicolumn{5}{|c|}{ Correlations } \\
\hline & & & DISIPUN & KESELAMATAN \\
\hline \multirow[t]{6}{*}{ Spearman's tho } & DISIPLIN & $\begin{array}{l}\text { Correlation } \\
\text { Coefficiert }\end{array}$ & 1.000 & .5 \\
\hline & & Sig. (2-aileof) & & .000 \\
\hline & & $N$ & 56 & 56 \\
\hline & KESELAMATAN & $\begin{array}{l}\text { Correiation } \\
\text { Coeficiert }\end{array}$ & $.513^{-}$ & 1.000 \\
\hline & & Sig. (2-taileof) & .000 & \\
\hline & & $N$ & 56 & 56 \\
\hline
\end{tabular}

Berdasarkan tabel di atas Koefisien korelasi antara disiplin kendaraan bermotor dengan keselamatan berlalu lintas sebesar 0,513 intepretasi cukup kuat, dan arah positif menunjukan bahwa variable Disiplin pengendara dengan variable Keselamatan berkorelasi secara signifikan artinya semakin tinggi disiplin semakin tinggi pula tingkat keselamatan, tanda bintang satu menunjukan bahwa korelasi antara variable X ( Disiplin) dengan Y ( Keselamatan ) adalah signifikan pada tingkat kesalahan 0,01 (1\%) dan kepercayaan 99\%.

\section{KESIMPULAN DAN IMPLIKASI}

Berdasarkan Analisis Evaluasi Kebijakan Peraturan Daerah Kota Bogor No 12 Tahun 2009 Tentag Kawasan Tanpa Rokok (Studi Kasus Pelaksanaan Kawasan Tanpa Rokok Pada Sekolah Menengah Atas Negeri Di Kota Bogor) dapat disimpulkan bahwa:

1. Efektivitas dalam Evaluasi Kebijakan Peraturan Daerah Kota Bogor No 12 Tahun 2009 Tentag Kawasan Tanpa Rokok (Studi Kasus Pelaksanaan
Kawasan Tanpa Rokok Pada Sekolah Menengah Atas Negeri Di Kota Bogor) diperoleh skor sebesar 3,86 yang menurut penafsiran berada pada kategori baik. Hal ini dikarenakan pemahaman tentang peraturan ini telah dipahami dengan baik dan kebijakan ini telah dianggap berhasil dilakukan.

2. Efisiensi dalam Evaluasi Kebijakan Peraturan Daerah Kota Bogor No 12 Tahun 2009 Tentag Kawasan Tanpa Rokok (Studi Kasus Pelaksanaan Kawasan Tanpa Rokok Pada Sekolah Menengah Atas Negeri Di Kota Bogor) diperoleh skor 3,12 yang menurut penafsiran berada pada kategori sedang. Hal ini didukung dengan proses soialisasi yang baik. Namun konsistensi pengawasan masih dianggap sangat kurang dan penerapan sanksi yang sudah cukup baik dilakukan.

3. Pemerataan dalam Evaluasi Kebijakan Peraturan Daerah Kota Bogor No 12 Tahun 2009 Tentag Kawasan Tanpa Rokok (Studi Kasus Pelaksanaan Kawasan Tanpa Rokok Pada Sekolah Menengah Atas Negeri Di Kota Bogor) diperoleh skor 3,06 yang menurut penafsiran berada pada kategori sedang. Hal ini dikarenakan pendisribusian biaya, fasilitas dan sumber daya manusia yang cukup untuk pelaksanaan kebijakan kawasan tanpa rokok di sekolah.

4. Responsvitas dalam Evaluasi Kebijakan Peraturan Daerah Kota Bogor No 12 Tahun 2009 Tentag Kawasan Tanpa Rokok (Studi Kasus Pelaksanaan Kawasan Tanpa Rokok Pada Sekolah Menengah Atas Negeri Di Kota Bogor) diperoleh skor 3,66 yang menurut penafsiran berada pada kategori baik. Hal ini dikarenakan Peraturan Daerah ini telah memberikan manfaat yang baik bagi lingkungan sekolah.

5. Ketepatan dalam Evaluasi Kebijakan Peraturan Daerah Kota Bogor No 12 Tahun 2009 Tentag Kawasan Tanpa Rokok (Studi Kasus Pelaksanaan Kawasan Tanpa Rokok Pada Sekolah Menengah Atas Negeri Di Kota Bogor) 
diperoleh skor 3,76 yang menurut penafsiran berada pada kategori baik. Hal ini dikarenakan kebijakan ini telah memberikan manfaat yang baik dan menurunkan jumlah pelanggaran yang terjadi di sekolah.

Hasil penelitian ini menunjukan bahwa Evaluasi Kebijakan Peraturan Daerah Kota Bogor No 12 Tahun 2009 Tentang Kawasan Tanpa Rokok (Studi Kasus Pelaksanaan Kawasan Tanpa Rokok Pada Sekolah Menengah Atas Negeri Di Kota Bogor) diperoleh skor akhir 3,50 yang menurut penafsiran berada pada kategori baik. Hasil ini berdasarkan rekapitulasi seluruh dimensi yang ada.

\section{DAFTAR PUSTAKA}

Arikunto, Suharsini (2006). Prosedur Penelitian Suatu Pendekatan Praktik, Jakarta: Rineka Cipta.

Handoko T. Hani Handoko (2012). Manajemen Personalia \& Sumber Daya manusia. Yogyakarta : University Press

Direktorat Jenderal Perhubungan Darat (1999). Rekayasa Lalulintas.

Malayu S.P Hasibuan (2014). Manajemen Sumber Daya Manusia, Bumi Aksara.

Sugiyono (2012). Metode Penelitian Administrasi, Bandung: Alfabeta.

Sugiyono (2014).Metode Penelitian Kuantitatif Kualitatif dan $R \& D$. Bandung: Alfabeta.

\section{Sumber Dokumen :}

Undang-Undang Republik Indonesia Nomor 22 Tahun 2009 tentang Lalulintas dan Angkutan Jalan

Peraturan Pemerintah Nomor 43 tahun 1993 Tentang Prasarana Lalulintas Jalan

Peraturan Daerah Kota Bogor Nomor 3 Tahun 20013. Tentang Penyelenggaraan Angkutan dan Jalan.
Peraturan Walikota Bogor Nomor 51 Tahun 20014. Tentang Tugas Pokok dan Fungsi DLLAJ 